\title{
A Dimensão Subjetiva da Subcidadania: Considerações Sobre a Desigualdade Social Brasileira
}

Luane Neves Santos, Alessivânia Márcia

Assunção Mota \& Marcus Vinícius de Oliveira Silva

Universidade Federal da Bahia

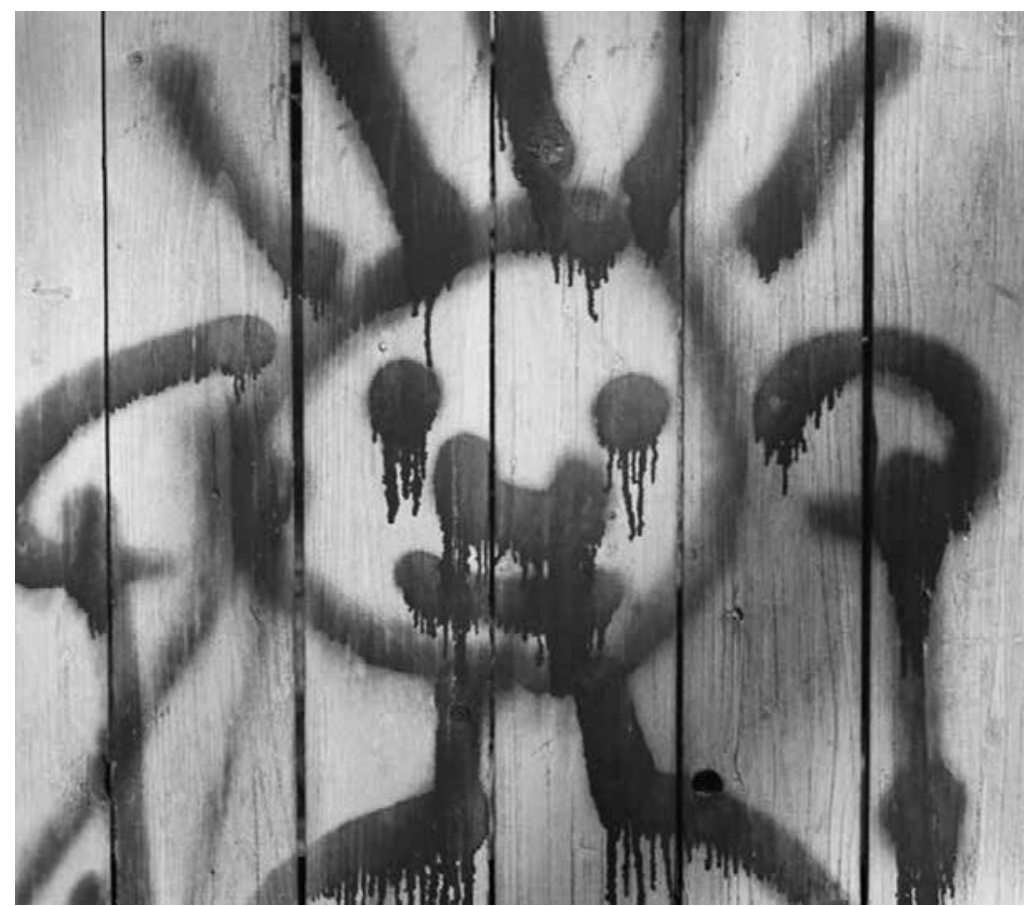


Resumo: Este artigo aborda a temática da desigualdade social e suas repercussões na subjetividade dos brasileiros, a partir de um esforço integrativo para superar a visão objetivista do fenômeno. Para tanto, recorre às proposições da sociologia de Jessé Souza e da psicologia de Gonzalez Rey, visando a um enriquecimento da compreensão dos processos sociopsicológicos que se fazem presentes nesse fenômeno, normalmente percebido por um viés exclusivamente economicista. O artigo adota, como ponto de partida, os esforços explicativos de Jessé Souza, sobretudo em sua descrição do caráter orgânico da desigualdade social brasileira, que tem como consequência a produção de uma subespécie humana; de Gonzalez Rey, extrai os elementos simbólicos, valorativos e relacionais da produção subjetiva da desigualdade, consolidada cotidianamente em práticas coletivas que a naturalizam. Torna-se necessário alinhar esforços interpretativos para a compreensão da desigualdade social a partir de perspectivas superadoras da dicotomia indivíduosociedade, pois, assim como a construção social da subcidadania - bem como os demais efeitos do modo como a desigualdade social se consolidou e se retroalimenta no Brasil - tem um componente estrutural relativo à subjetividade social, esta também se perpetua pela ação pré-reflexiva de cada sujeito na vivência de sua subjetividade individual.

Palavras-chave: Subjetividade. Iniquidade social. Psicologia social. Exclusão social.

\begin{abstract}
This article deals with the theme of social inequality and its repercussion on the subjectivity of Brazilians, based on an integrational effort for the overcoming of the objectivist vision of the fenomena. To do so, it makes use of the proposals of Jessé Souza, sociologist, and of Gonzalez Rey's psychology, having in mind a better comprehension of the socio-psychological processes that take part in this fenomena, which are many times perceived and biased by economists. The article adopts as a start point the many explanations of Jessé Souza, mainly his descriptions of the inequality in the Brazilian society, which has as a consequence the outcome of a "human sub-citizenship". I took the symbolic elements used by Gonzales Rey which have the same values and are also related to a formation of a subjective social inequality, consolidated on day to day group practices. It is therefore necessary to put together several interpretations in order to better understand what social inequality is. Taking into account the different perspectives that overcome the dichotomy individual-society - as the construction of the social sub-citizenship as well as the other effects on how social inequality has been consolidated and has a feedback in Brazil - there is a structural component related to the social subjectivity, being the latest also perpetuated through the prereflexive action of each individual, on each individual subjective experience.
\end{abstract}

Keywords: Subjectivity. Social issues. Social psychology. Social exclusion.

Resumen: Este artículo reflexiona sobre la temática de la desigualdad social y sus repercusiones en la subjetividad de los brasileros, a partir de una esfuerzo integrativo para superación de la visión objetivista del fenómeno. Para eso, se recurre a las proposiciones de la sociología de Jessé Souza y de la psicología de Gonzalez Rey visando un enriquecimiento de la comprensión de los procesos socios psicológicos que se hacen presentes en este fenómeno, normalmente percibido por un enfoque exclusivamente economicista. Adopta como punto de partida, los esfuerzos explicativos de Jessé Souza, principalmente en su descripción del carácter orgánico de la desigualdad social brasilera, que tiene como consecuencia la producción de una "sub-especie humana". De Gonzalez Rey se extraen los elementos simbólicos, valorativos y relacionales de la producción subjetiva de la desigualdad, consolidada cotidianamente en prácticas colectivas que la naturalizan. De esta manera, se vuelve necesario alinear esfuerzos interpretativos para la comprensión de la desigualdad social a partir de perspectivas superadoras de la dicotomía individuo - sociedad, pues, al paso en que la construcción social de la subciudadanía - así como los demás efectos del modo como la desigualdad social se consolidó y se retroalimenta en el Brasil - tiene un componente estructural relativo a la subjetividad social, la subjetividad social también se perpetua por la acción pre-reflexiva de cada sujeto en la vivencia de su subjetividad individual.

Palabras clave: Subjetividad. Problemas sociales. Psicología social. Exclusión social.

O presente artigo tem por objetivo discutir o tema da desigualdade social e suas repercussões na subjetividade dos brasileiros a partir da perspectiva sociológica de Jessé Souza e psicológica de Gonzalez Rey, com vistas a compreender a dimensão subjetiva da subcidadania e o processo de retroalimentação da desigualdade social no Brasil. A aproximação teórica entre os autores pode ser de grande utilidade, na medida em que, oriundos de matrizes disciplinares distintas, a saber, a Psicologia e as ciências sociais, ambos se movimentam no sentido de evidenciar as suas insatisfações com os limites 
impostos pela dicotomia sujeito/sociedade que a tradicional distinção entre essas matérias produz, condição que possibilita melhor compreender as implicações psicossociais da desigualdade social na construção das subjetividades referida tanto aos indivíduos quanto às coletividades.

A desigualdade social é um tema complexo que pode ser abordado por diferentes perspectivas. Em geral, evidenciada pelas dimensões econômicas objetivas, sobretudo na diferença da distribuição da renda, ela inclui também dimensões relativas a aspectos existenciais, a relações sociais e a expressão política (Souza, 2006a). O histórico acesso diferenciado a recursos, tanto de ordem material como simbólica, caracteriza o contexto no qual as pessoas se desenvolvem e constroem suas subjetividades.

No caso brasileiro, a desigualdade social apresenta-se historicamente como um grave problema, ainda que com um cenário promissor a partir das políticas públicas direcionadas para a área social que foram implementadas pelo governo Lula. De acordo com o Instituto Brasileiro de Geografia e Estatística - IBGE (2010), na pesquisa sobre indicadores de desenvolvimento sustentável, o Brasil permanece com elevado índice de Gini (0.531 em 2008), que mede o grau de concentração na distribuição de rendimentos da população e varia de 0 (zero), situação de plena igualdade, a 1 (um), conjuntura de desigualdade máxima. Em condições reais, é muito difícil que o índice alcance esses valores extremos, porém, um índice em torno de 0,5 é compreendido como um valor expressivo de fortes desigualdades na distribuição de renda na região analisada.

O que se observa, portanto, é que o crescimento econômico no País não reduziu a desigualdade social na mesma proporção. Dados do IBGE revelam, por exemplo, que, entre 1996 e 2006, o PIB per capita cresceu
$11,2 \%$, enquanto o índice de Gini diminuiu $7,1 \%$. Outro fator importante nesse contexto são as diferenças regionais destacadas pelo indicador: maior no Centro-Oeste $(0,558)$ e menor nas Regiões Norte e Sul $(0,498)$ em 2008 .

Assim, fortes desigualdades na distribuição de renda implicam a consolidação da pobreza e situam-se entre os problemas mais graves do País. Estados como Piauí, Paraíba e Alagoas, que possuem os maiores índices de Gini do Brasil, por exemplo, apresentam proporções elevadas de famílias com rendimento mensal familiar per capita inferior a $1 / 2$ salário mínimo: $44,1 \%, 42,2 \%$ e $47,6 \%$, respectivamente (IBGE, 2010).

A despeito da melhoria dos índices de desigualdade social, estes ainda permanecem muito altos e como um grande desafio à sociedade brasileira. Dados divulgados pela Fundação Getúlio Vargas na pesquisa intitulada Desigualdade de Renda na Década (Neri, 2011) destacam uma redução na pobreza de 50,64\% entre dezembro de 2002 e 2010 e do índice que mede a desigualdade, que chegou ao mínimo em uma série histórica desde 1960. A taxa de crescimento na última década dos $50 \%$ mais pobres foi $577 \%$ mais alta que a dos $10 \%$ mais ricos.

Conforme assinalado por Neri, a desigualdade social se constitui em níveis e distâncias desiguais entre as pessoas, quer seja de um ponto de vista referido à totalidade da população - desigualdade vertical - quer seja entre segmentos específicos dessa população, a partir de gênero, escolaridade, etnia desigualdade horizontal.

Quanto ao estudo, por parte da Psicologia brasileira, de temas associados à desigualdade social, observa-se que os psicólogos, ainda que tardiamente, têm se interessado progressivamente pela questão, exigindo a ampliação dos estudos nessa temática, dada 
A noção de subcidadania implica uma hierarquia

valorativa das pessoas - implícita e enraizada institucionalmente de modo invisível

- que determina

quem é ou não gente, e, por consequência, quem é ou não cidadão. Tal

processo incide fundamentalmente nos acessos diferenciados aos recursos materiais e simbólicos na vida social (Souza, 2003). sua grande relevância social. Destaca-se como um dos pioneiros o trabalho de Patto (1984), que, ao analisar a Psicologia e as classes subalternas, produz uma importante reflexão crítica sobre a teoria da carência cultural como modelo explicativo das dificuldades de inserção social das classes pobres. Produções mais atuais evidenciam de forma mais específica os entrelaçamentos entre a experiência de subalternidade e as implicações subjetivas de tal condição. Entre estes, incluem-se os estudos sobre a dimensão subjetiva dos fenômenos sociais (Bock \& Gonçalves, 2009), a invisibilidade pública (Costa, 2004), o sofrimento éticopolítico (Sawaia, 2001) e a humilhação social (Gonçalves Filho, 1998).

Convergentes, a leitura psicológica de Spink e Spink (2005) e a tomada sociológica de Souza (2006a) sobre o tema apontou que há muitos mecanismos mantenedores da desigualdade social no Brasil, com destaque para o processo de naturalização que a envolve. Nessa perspectiva, a desigualdade social é percebida como uma construção coletiva, consolidada cotidianamente nas relações estabelecidas pelos sujeitos a partir das práticas sociais reiteradas pelas crenças e valores. Acrescenta-se ainda que, em países periféricos como o Brasil, a desigualdade social toma contornos perversos, dada a condição de miséria e de subcidadania vivenciada por amplas camadas da sociedade.

A noção de subcidadania implica uma hierarquia valorativa das pessoas - implícita e enraizada institucionalmente de modo invisível-que determina quem é ou não gente, e, por consequência, quem é ou não cidadão. Tal processo incide fundamentalmente nos acessos diferenciados aos recursos materiais e simbólicos na vida social (Souza, 2003). Assim, o compartilhamento de uma dada estrutura psicossocial apresenta-se como a base tácita do reconhecimento social, entendido como atribuição de respeito e deferência, reportando-se à noção moderna de cidadania jurídica e política (Souza, 2006b).

A desigualdade social produz fortes ressonâncias na constituição da subjetividade, tanto individual quanto social. Para Rey (2005a), a subjetividade é configurada como unidades representativas das sínteses das histórias individuais associadas a elementos das histórias coletivas, a partir das quais a subjetividade se organiza. Nessa perspectiva, a subjetividade apresenta um caráter sistêmico e compreende a expressão do sujeito como manifestação da subjetividade individual, susceptível a mudanças a depender do contexto da subjetividade social.

Ao adotar um conceito de subjetividade distanciado da compreensão comumente utilizada - associada aos aspectos intrapsíquicos do sujeito, determinante das ações humanas e dissociada do contexto social - busca-se uma reflexão que abranja o tema em sua complexidade, entendendo-o como um campo de significação heurística ao permitir um diálogo permanente com todos os níveis constitutivos da realidade social e dos sujeitos imersos nesse contexto.

Discutiremos a seguir a temática da desigualdade social e da subcidadania distanciando-nos desse viés econômico, focados na sua relevância para a construção da subjetividade em seus vários ângulos, enfatizando componentes tanto de ordem social quanto psicológica, no intuito de problematizar a questão e de contribuir para implicação de todos na construção de alternativas teóricas e práticas às perspectivas vigentes.

\section{A construção social da subcidadania no contexto da desigualdade social brasileira}

A compreensão de Jessé Souza sobre as características constitutivas do Brasil levaram- 
Para Souza

(2006b), a desigualdade social no País é naturalizada a tal ponto na vida cotidiana que esta se torna pouco acessível à percepção, permanecendo invisível. no a produzir uma série de trabalhos direcionados a uma reinterpretação da formação social do País, propondo o desenvolvimento de uma importante teoria social crítica sobre a desigualdade social brasileira e seus desdobramentos nos âmbitos individuais e coletivos. Para Souza (2006b), a desigualdade social no País é naturalizada a tal ponto na vida cotidiana que esta se torna pouco acessível à percepção, permanecendo invisível. Assim, a percepção da existência de pessoas pobres e miseráveis é obscurecida por um arsenal de justificativas que normalizam as condições precárias de existência de um segmento da população, como, por exemplo, as ideias de meritocracia, de trajetórias pessoais fracassadas, de sorte ou azar.

Nesse sentido, para o referido autor, a marginalização constante de grupos sociais inteiros correlaciona-se com a disseminação ativa de certas compreensões morais e políticas na sociedade. Dentre estas, a noção que reduz a causa da marginalidade à possibilidade de resolução do problema por via exclusivamente econômica é um bom exemplo, pois oculta a dimensão fundamental das relações sociais moldadas a partir de critérios que atribuem reconhecimento social para uns e marginalidade para outros, de um processo que alia cidadania e subcidadania (Souza, 2006b).

Para fundamentar seus argumentos teóricos sobre a constituição de um padrão nomeadamente periférico de cidadania e subcidadania, Souza (2003) recorre à matriz sociológica oriunda de Charles Taylor e de Pierre Bourdieu. Do primeiro autor, ele recupera as formulações sobre a teoria do reconhecimento social, e do último, as noções de habitus e de distinção. Ademais, ao retomar o contexto histórico que favoreceu a emergência desses padrões no Brasil, ele apresenta as considerações de Florestan Fernandes sobre a integração do negro na sociedade de classes, acrescentando novas proposições. Nessa obra, Fernandes (1978) produz um significativo relato sobre a inserção social do negro após a abolição da escravatura, na cidade de São Paulo.

Souza destaca sua convergência com a perspectiva apresentada por Fernandes, de que faltava fundamentalmente ao ex-escravo uma organização psicossocial para adaptarse à nova ordem social pós-abolição, que é inerente à atividade capitalista e requer uma pré-socialização em um sentido específico. Trata-se da não adaptação do negro para o trabalho livre e da sua inaptidão para operar de acordo com modelos de comportamento e de personalidade da sociedade competitiva.

Tal dificuldade de adaptação pode ser compreendida, uma vez que os negros foram libertos, porém não incluídos na vida social. Além disso, ao retomar Florestan, Souza alerta que a política escravocrata brasileira criava obstáculos a qualquer modo de organização familiar ou comunitária entre os escravos. Aproximando-se de Fernandes, considera que a desorganização de âmbito familiar repercute decisivamente na constituição de um padrão de ação desorganizada na vida social, inicialmente atribuída a negros e mulatos, mas que historicamente foi decisivo para a constituição de uma ralé estrutural no Brasil.

Na obra de Jessé, o termo ralé compõe uma categoria teórica de cunho metafórico, que se refere a uma classe de indivíduos desprovidos não somente do capital cultural e econômico mas também fundamentalmente sem acesso às pré-condições sociais, morais e culturais que permitem essa apropriação (Souza, 2009). Por inspiração de Elias (1994), tais pré-condições constituem o terreno em que objetividade e subjetividade se interpenetram no processo histórico. O termo é utilizado em tom provocativo, sem a intenção de ofender ou de humilhar as pessoas que compõem esse grupo social (Souza, 2009). 
Nesse ponto, Souza amplia os horizontes acerca das hipóteses explicativas sobre a marginalidade do negro na sociedade brasileira, a qual, na sua visão, é prototípica dos modos de expressão da marginalidade que se estende sobre a ralé. Desse modo, acentua a possibilidade de compreender as contribuições teóricas de Florestan à luz da constituição e da reprodução de um habitus específico. O habitus compreende um sistema de estruturas cognitivas e motivadoras, que produz um esquema de condutas e de comportamentos que passa a gerar práticas individuais e coletivas.

Segundo Bourdieu (2009), o habitus constitui em um sistema de disposições e de estruturas duráveis e transponíveis, princípio gerador e organizador das práticas individuais e coletivas, de acordo com os esquemas engendrados pelos grupos dominantes. Cada experiência, ao ser depositada nos organismos sob a forma de esquemas de percepção, de pensamento e de ação, tende, de forma mais segura que todas as regras formais e normas explícitas, a garantir a conformidade das práticas e sua constância ao longo do tempo.

Bourdieu afirma que a dinâmica de produção simbólica na vida dos sujeitos não ocorre arbitrariamente; ao contrário, essas produções seriam provenientes desse sistema dominante e legitimador das preferências, estilos, formas de ser, pensar e atuar, que se incorporariam nos sujeitos de uma forma tão sedimentada, complexa e mascarada que o processo de dominação e de opressão tenderia a se tornar legítimo. Como produto da ação dominante do sistema, o habitus permitiria a produção livre de todos os pensamentos, percepções e ações, fazendose, entretanto, nos limites inerentes às condições particulares de sua produção (Souza, 2003), isso porque o habitus possui uma capacidade infinita de engendrar uma liberdade controlada, condicional e condicionada às ações dos sujeitos em bases historica e socialmente situadas.

A noção de habitus permite desvelar a força das construções ideológicas presentes na sociedade, os processos de constituição dos sujeitos baseados na naturalização e na banalização das desigualdades, reproduzidas e aceitas pelos próprios sujeitos, e nos mecanismos utilizados para legitimá-las como boa e justa, em outras palavras, compreender a persuasão invisível como produto de uma pedagogia implícita que atua sutilmente nos detalhes cotidianos considerados de menor importância (andar, vestir, falar, consumir, etc.) que vai inscrevendo-se e naturalizandose, de forma imperceptível e inconsciente, em toda uma estrutura social. Nesse uso que faz de Bourdieu, a construção de Jessé Souza distancia-se das compreensões economicistas para valorizar aspectos que são normalmente considerados em dimensões subjetivas.

O uso do conceito de habitus na obra do autor é fundamental, pois amplia a explicação da marginalidade localizada no preconceito de cor, alertando para a centralidade da reprodução de um habitus precário como causa principal da inadaptação e da marginalização desses grupos. Ao propor tal compreensão, o referido autor não descarta a existência do preconceito, apenas destaca que, para além da cor, existe um preconceito que remete a um tipo específico de personalidade, expressa na ralé, avaliada como improdutiva e disruptiva para a sociedade como um todo.

Em consequência, o problema não está somente na cor, mas na inadaptação social. Nesse ponto, Souza (2003) sinaliza uma ruptura teórica com Florestan, ampliando a discussão proposta por esse autor ao produzir a tensão cor versus habitus. Para apoiar tal interpretação, Souza retoma os achados de Fernandes, que comparam as condições de inadaptação da população negra às dos 
dependentes rurais brancos, combinando esses dois elementos como formadores da "gentinha" ou da "ralé" nacional.

Refletir sobre a tensão cor/habitus exige, portanto, a ação de debruçar-se sobre o componente oculto por trás da cor. Segundo Souza (2003), Florestan indica o caminho a ser seguido através da repetição constante em seu trabalho, de que o que os negros queriam essencialmente era transformarse e "ser gente". Nesse sentido, ser gente pode ser comparado às pré-condições para a constituição de um habitus apropriado às necessidades institucionais da nova ordem, independentemente da cor de pele; esse ser gente, no caso, expressa as lutas por reconhecimento, pré-condição social para a configuração e a expressão dos selfs individuais.

Ao aprofundar a discussão sobre o habitus, Souza propõe uma subdivisão interna de tal categoria com vistas a atribuirIhe um caráter histórico mais matizado: habitus precário, primário e secundário. Por habitus primário, ele compreende os esquemas avaliativos e as disposições de comportamento objetivamente absorvidos e incorporados, como proposto na perspectiva bourdieusiana do termo, que possibilita o compartilhamento entre as pessoas de uma noção de dignidade, no sentido tayloriano:

1 Quando Souza refere-se ao aspecto europeu, não está remetendo-se à entidade concreta da Europa, nem a um tipo físico específico, mas destacando a fonte histórica da concepção culturalmente assentada de ser humano, que se apresenta de forma hegemônica por meio da ação empírica de instituições como mercado competitivo e Estado racional centralizado.
É essa dimensão da 'dignidade' compartilhada, no sentido não jurídico de 'levar o outro em consideração', e que Taylor chama de respeito atitudinal, que tem que estar disseminada de forma efetiva numa sociedade para que possamos dizer que, nessa sociedade concreta, temos a dimensão jurídica da cidadania e da igualdade garantida pela lei. Para que haja eficácia legal da regra de igualdade, é necessário que a percepção da igualdade na dimensão da vida cotidiana esteja efetivamente internalizada (2003, p. 166)
O habitus precário pode ser compreendido como um modo de organização da personalidade dotado de disposições de comportamento insuficientes para as demandas objetivas para que, seja um indivíduo, seja um grupo social, possa ser considerado produtivo e útil em uma sociedade moderna e competitiva. Tal processo instaura um tipo de validação ao sujeito, que passa a usufruir de reconhecimento social e de seus correlatos. No entanto, a vivência do habitus precário, como elemento fundamental na construção de uma ralé estrutural, só se apresenta como um fenômeno de massa em países periféricos como o Brasil (Souza, 2003).

Já o habitus secundário parte da homogeneização dos pressupostos atuantes na constituição do habitus primário, acrescentando critérios classificatórios de distinção social com base no conceito de gosto, desenvolvido por Bourdieu (2007). Nesse aspecto o gosto ganha a qualidade de uma moeda invisível, que transforma o capital econômico puro e, sobretudo, o capital cultural em um conjunto de signos sociais de distinção legítima. Destaca-se ainda que esse processo de luta pela distinção, firmada no que Souza denomina habitus secundário, existe tanto em sociedades periféricas quanto nas avançadas, pois associa-se à apropriação seletiva de bens e de recursos escassos.

A noção de subcidadania instaura um grande desconforto quando analisada a partir de uma perspectiva individual, por meio do questionamento de como esse processo se apresenta em nossas relações sociais. Nesse sentido, Souza ressalta que não se trata de intencionalidade, porque

nenhum brasileiro europeizado ${ }^{1}$ de classe média confessaria, em sã consciência, que considera seus compatriotas das classes baixas não-europeizadas 'sub-gente'. Grande parte dessas pessoas votam em partidos de esquerda e participam de campanhas contra a fome e coisas do gênero. A dimensão aqui é objetiva, 
O ideal

de justiça, apresentado pelo mundo

moderno,

fundamenta-se na meritocracia

- entendida

como a

possibilidade

de os indivíduos

superarem as

barreiras sociais,

econômicas

e culturais

existentes -

desconsiderando

a real natureza

desses

obstáculos

(Souza, 2003). sub-liminar, implícita e intransparente. Ela é implícita também no sentido de que não precisa ser linguisticamente mediada ou simbolicamente articulada. Ela implica, como a idéia de habitus em Bourdieu, toda uma visão de mundo e uma hierarquia moral que se sedimenta e se mostra como signo social de forma imperceptível a partir de signos sociais aparentemente sem importância, como a inclinação respeitosa e inconsciente do inferior social quando encontra com um superior, pela tonalidade da voz mais do que pelo que é dito, etc (Souza, 2003, p. 175)

Propor a noção de múltiplos habitus tem por objetivo superar concepções subjetivistas da realidade que restringem a mesma às interações face a face. Ademais, a falta de reconhecimento não implica somente a ausência do devido respeito a alguém. Ela produz feridas profundas, incidindo nas vítimas também por meio do autodesprezo. E, na maioria das vezes, a aceitação da situação de precariedade como legítima e até merecida corrobora a naturalização da desigualdade, mesmo em casos de desigualdade extrema como na sociedade brasileira (Souza, 2003).

Para Souza, o fundamento principal daqueles que visualizam na classe social um elemento que não impacta na performance social dos sujeitos é o pressuposto do desempenho e da disciplina. A anuência e a internalização generalizada desse princípio individualista tornam-se as responsáveis pela percepção de fracasso pessoal como modelo explicativo da inadaptação e da marginalização desses setores. Ressalta-se ainda que a disseminação dessa visão ocorre tanto pelas parcelas dominantes na sociedade como também pelas próprias vítimas.

Pressupõe-se que o marginalizado seja portador das mesmas capacidades disposicionais do indivíduo da classe média (Souza, 2003). No entanto, a reprodução de classes marginalizadas vincula-se ao cultivo das pré-condições morais, culturais e políticas da marginalidade, pois a miséria dos desclassificados é moldada não apenas sob a forma de miséria econômica mas também sob a forma de miséria emocional, existencial e política, que são naturalizadas (Souza, 2006a). O ideal de justiça, apresentado pelo mundo moderno, fundamenta-se na meritocracia - entendida como a possibilidade de os indivíduos superarem as barreiras sociais, econômicas e culturais existentes - desconsiderando a real natureza desses obstáculos (Souza, 2003). Assim, o indivíduo privilegiado por um aparente talento inato seria, na verdade, produto de capacidades e de habilidades transmitidas de pais para filhos por mecanismos de identificação afetiva por meio de exemplos cotidianos, assegurando a reprodução de privilégios de classe indefinidamente no tempo (Souza, 2009), ainda que tais aspectos possam figurar como pressupostos latentes ou inconscientes.

Souza considera que esse poderoso processo de identificação emocional e afetiva desempenhe uma larga vantagem na competição social, em relação à ralé, seja na escola, seja no mercado de trabalho, em relação às classes desfavorecidas. A ralé, ao dispor apenas do corpo para sua reprodução, não apresentaria condições de atender as demandas de um mercado competitivo, globalizado, exigente e segregador, sem paralelo mesmo quando se faz alusão ao lumpenproletariado marxista, que funcionava como um exército industrial de reserva que, em épocas de crescimento econômico poderia ser absorvido pelo capital (Marx, 1988).

Ao pulverizar a discussão sobre a desigualdade social brasileira, outras teses colaboram para o seu processo de naturalização, desfocando os componentes subjetivos através de um jogo de prestidigitação objetivista: 1) ênfase excessiva nas cruzadas contra a corrupção, desconsiderando que esse é um problema 
das sociedades modernas como um todo, 2) foco em reformas administrativas, como se o problema de base fosse somente de gestão apropriada dos recursos, 3) destaque nas diferenças regionais, que conduzem a uma luta contra as elites retrógradas, como se as regiões mais modernas não enfrentassem problemas semelhantes, e, sobretudo, 4) a crença fetichista na capacidade da economia em solucionar todos os problemas (Souza, 2003).

Nessa hipótese, viveria a sociedade brasileira, liberada do potencial horror associado ao seu caráter perverso, um tipo sui generis de estratificação, no qual as classes sociais são demarcadas não somente pela renda mas, sobretudo, pela capacidade diferencial dos sujeitos de dispor dos recursos tanto materiais quanto simbólicos, o que termina por retroalimentar o processo de desigualdade social no País (Souza, 2009).

\section{A subjetividade em uma perspectiva superadora da dicotomia indivíduo-sociedade}

Ao afirmar que o ponto principal é saber porque as pessoas sentem o que elas sentem e qual a dinâmica social que produz, de maneira tão avassaladora, esse tipo de humilhação e de baixa auto-estima para determinada classe de pessoas, Souza (2006c) nos propõe a concepção de uma nova teoria crítica da sociedade. Nesta, associa-se uma percepção de subjetividade que intenciona explicitar a dinâmica das causas que produzem dor, desrespeito, não reconhecimento e humilhação para uns e legitimação, prazer e saúde para outros.

Souza associa-se a outras iniciativas sociológicas tais como a de Bernard Lahire, no artigo intitulado Esboço do Programa Científico de uma Sociologia Psicológica, no qual indica a importância de que os estudos sociológicos possam incorporar a perspectiva da vivência concreta dos sujeitos, ou, como ele afirma, "estudar o social individualizado, isto é, o social refratado em um corpo individual - cuja peculiaridade é atravessar os diferentes grupos, instituições, campos de forças e de lutas e cenas -, é estudar a realidade social sob a forma incorporada, interiorizada" (Lahire, 2008, p. 375).

A compreensão dos aspectos da subjetividade dos brasileiros, configurada a partir dos elementos característicos do processo de desenvolvimento social deste país, tornase fundamental para o entendimento das múltiplas formas pelas quais os sujeitos vêm experienciando, sentindo e expressando tais tensionamentos, contradições e determinações em sua complexidade.

Abordar o tema da subjetividade atualmente pressupõe um convite à subversão do seu significado e limites de compreensão, circunscritos, até então, pelas ciências humanas e pelo senso comum. Quando se questiona o significado do termo ou se recorre aos dicionários e enciclopédias, é frequente encontrarmos uma polissemia que tende a incorrer em compreensões divergentes e algumas vezes limitantes em sua capacidade explicativa sobre as práticas humanas socialmente construídas. As definições comumente encontradas referemse a "íntimo", "pessoal", "o que não se acessa", "interior", "o que não é objetivo" ou ainda "é muito subjetivo para ser explicado".

Conforme análise de Figueiredo e Santi (2003), a subjetividade foi compreendida inicialmente como as experiências individuais sentidas e vividas como únicas e originais, quase incomunicáveis e inacessíveis a outras experiências. O seu estudo relaciona-se a questões filosóficas referentes à busca da origem dos seres, da existência, dos desejos, experiências, sentimentos e valores, sendo denominada por esses autores subjetividade 
privatizada, a qual refletia a visão predominante do pensamento liberal vigente no final do século XVIII. Inicialmente legitimada pelo campo filosófico, a subjetividade privatizada demarcava uma distinção entre os processos íntimos da alma (relacionados à essência do eu, à interioridade do pensamento) e os processos do corpo (sujeitos às mesmas leis físicas e orgânicas).

A crença na existência de um polo objetivo e de um polo subjetivo, de um mundo interno e de um mundo externo produz a percepção nos sujeitos de que são seres únicos, singulares e individualizados, sem relação, contudo, com o mundo real e objetivo, o que leva a compreensão desses sujeitos a ancorar-se em aspectos dicotômicos e muitas vezes incomunicáveis entre objetividade/ subjetividade, corpo/mente, razão/emoção, indivíduo/sociedade, inclusão/exclusão (Figueiredo \& Santi, 2003).

Baseando-se nos trabalhos desenvolvidos por Lev Semenovitch Vygotsky, Rey (2005a) buscou explicar a complementaridade entre o cognitivo, o afetivo, o social e o individual, distanciando-se teórica, epistemológica e metodologicamente das explicações propostas tradicionalmente pelas ciências humanas para a compreensão da psique. No desenvolvimento da teoria sobre a subjetividade, surge em Gonzalez Rey a necessidade de elaborar uma nova perspectiva epistemológica e metodológica de produção de conhecimento da subjetividade, resgatando a centralidade dos sujeitos, a construção do conhecimento de forma interativa entre pesquisador e sujeitos, além de uma perspectiva construtivointerpretativa do saber, guiada pelas categorias de configuração subjetiva, subjetividade individual, subjetividade social e sentido subjetivo (Rey, 2005c).

A concepção de subjetividade, movida pelo pensamento naturalista e positivista, incentivava o desenvolvimento de ações controladoras e previsíveis do comportamento humano, além de servir como suporte, ordenamento e regulação social. Referindose a obra de Vygotsky, Rey (2005b) destaca que ele, bem como seus seguidores, Luria e Leontiev, apresentavam fortes críticas às posições reducionistas sobre a compreensão da vida consciente, o incentivo à produção de uma psicologia dialética, uma correlação entre fenômeno subjetivo e fenômeno objetivo, além de afirmarem que o sujeito poderia ser melhor compreendido a partir de seu contexto cultural.

As concepções atuais de subjetividade redimensionam a importância dos aspectos sociais e coletivos para constituição dos sujeitos, aspectos esses que são construídos a partir da realidade social e expressos através dos significados, emoções, ideias, discursos, etc. Necessitam, por sua vez, na visão de Bock, Gonçalves e Furtado (2009), ser constantemente compreendidos, analisados e criticados, visando a desvelar os aspectos ideológicos que mascaram as relações sociais de dominação, desigualdade e manutenção do status quo.

A fundamentação teórica sobre subjetividade desenvolvida pelo psicólogo social cubano Fernando González Rey considera a afirmação superadora da dicotomia indivíduo/sociedade. É a partir dos conflitos e contradições vivenciados no contexto social revolucionário cubano que a teoria de Rey se desenvolve. Orientado pela perspectiva histórico-cultural, ele apresenta as categorias sujeito e subjetividade como "categorias subversivas", por acreditar, dentre outros motivos, que elas "legitimam o espaço e a tensão da diferença, reconhecendo assim o direito de posições distintas dos sujeitos individuais" (Martinez, 2005, p.28).

Rey (2005b) compreende a subjetividade como um sistema em desenvolvimento, 


\section{O sujeito \\ constituído por uma concepção dialética e complexa de homem torna- se o verdadeiro protagonista de sua história e da história coletiva construída simultaneamente, sendo também o responsável pelo próprio processo de subjetivação a partir dos contextos onde se encontra inserido \\ (Rey, 2005a).}

que integra o atual e o histórico, em cada momento de ação do sujeito nas diversas esferas de sua vida. Destaca ainda o autor que a subjetividade é um sistema dinâmico, cuja unidade central são as configurações de sentido, que integram o presente e o passado em cada momento de ação do sujeito. As configurações subjetivas organizam, portanto, a subjetividade como sistema e podem ser consideradas relativamente estáveis por estarem ligadas a uma produção de sentidos subjetivos que precede o momento presente da ação do sujeito e que contribui para a produção de sentidos de qualquer ação nova, que impacta na organização do sistema.

O sentido subjetivo se estabelece como um sistema psíquico qualitativamente distinto a partir da integração da emoção aos registros simbólicos (Rey, 2005b), em um alinhamento espacial e temporal que define o seu caráter socio-histórico. As conexões e os desdobramentos dos sentidos são variados e não adotam uma regra universal. Desse modo, o uso do termo configuração subjetiva é uma referência à organização desses complexos processos. O sentido subjetivo existe, por conseguinte, em um fluir na subjetividade, que toma formas diversificadas nas configurações subjetivas. Por isso, um sentido subjetivo pode participar, ao mesmo tempo, da composição de diferentes configurações e estar vinculado à produção de novos sentidos em cada uma delas, em um processo para além da consciência do sujeito (Rey, 2005b).

As configurações subjetivas do aspecto social não aparecem, portanto, como algo externo, em contraposição às configurações das subjetividades individuais, pois estas se constituem mutuamente, uma vez que não é possível considerar a subjetividade de um espaço social desatrelada da subjetividade dos indivíduos que a compõem. De modo análogo, não é possível compreender a constituição da subjetividade individual sem apreciar a subjetividade dos espaços sociais que colaboram para a sua construção (Martínez, 2005).

A subjetividade social permite compreender que os espaços coletivos apresentam uma dimensão simbólica, objetivada através das leis, valores, regras, significados, ideologias, teorias, discursos, ciências, etc. Assim, em cada momento histórico, as configurações subjetivas se apresentarão conforme se configurarem as relações sociais e as formas de produção da vida a que os sujeitos derem significado.

Segundo Rey (2005b, p. 203), a ação de um indivíduo em um determinado contexto social "poderá não apresentar repercussões imediatas, mas tende a ser correspondida por reações advindas dos outros integrantes desses espaços, impressas pelos processos de subjetivação característicos desse contexto, gerando assim zonas de tensão". Esse tensionamento característico da complexidade da organização social e da ação dos sujeitos nesses espaços (ações essas que apresentam elementos de sentido provenientes de outros espaços) pode proporcionar momentos de crescimento social e individual.

Desse modo, os sujeitos, ao desenvolverem diferentes tipos de atividades, constroem uma forma única e particular de produção de sentidos, constituindo, portanto, configurações subjetivas diferenciadas em suas expressões particulares. O sujeito constituído por uma concepção dialética e complexa de homem torna-se o verdadeiro protagonista de sua história e da história coletiva construída simultaneamente, sendo também o responsável pelo próprio processo de subjetivação a partir dos contextos onde se encontra inserido (Rey, 2005a).

A compreensão de sujeito em Rey dialoga com aspectos das formulações de Morin (2000) no que tange à necessidade de uma 
transcendência na concepção de indivíduo para compreender a noção de sujeito, visando a superar a simplicidade do primeiro para dar conta da complexidade do segundo. A compreensão de sujeito, nessa perspectiva, elegeria alguns princípios indispensáveis a seu processo de construção: autonomia, autorreferência, intencionalidade, unidade subjetiva/objetiva do sujeito, exclusão (na qual o eu é único para cada um) e inclusão (compreendida como a capacidade de agregar outros elementos na subjetividade) (Morin, 2000).

A concepção teórica de Gonzalez Rey estabelece uma subjetividade qualificada como mutável, dinâmica e polifórmica, que supera a dicotomia indivíduo/sociedade para que, mesmo sob condições estruturantes, seja possível aos indivíduos uma mobilidade dos sentidos e significados que integre as inquietações e os questionamentos, buscando compreender porque nos tornamos assim e não de outro jeito, e o mais importante, como fazermos para nos tornarmos de outro jeito e não permanecermos assim.

\section{A dimensão subjetiva da subcidadania}

A problemática situação de desigualdade social no Brasil, aliada aos esforços políticos da Psicologia como profissão de compromisso social (Bock, 1999), reforça a importância da produção de estudos que possam refletir sobre as dimensões subjetivas associadas à desigualdade social, buscando superar as perspectivas dicotômicas e o viés economicista.

Ainda que González Rey, psicólogo cubano residente no Brasil, não tenha tematizado especificamente a problemática da desigualdade social brasileira, seus determinantes históricos e suas ressonâncias nos processos de produção da subjetividade e a sua perspectiva histórico-cultural se coadunam com a dimensão subjetiva da desigualdade social teorizada por Jessé Souza.

Conforme visto anteriormente, a desigualdade social tem sido apresentada atualmente como uma questão de ordem essencialmente econômica. Essa visão enfatiza uma dimensão de base que não somente institui mas que também retroalimenta a desigualdade ao tornar legítimo o acesso diferenciado a recursos materiais e simbólicos a partir da hierarquia valorativa dos indivíduos em sub(cidadãos).

É preciso refletir por quais motivos, passados séculos de descobrimento, o Brasil continua na condição de nação periférica, cuja desigualdade é cotidianamente naturalizada, em que se convive perversamente com um exército de subcidadãos. É necessário, também, questionar-se sobre os reais interesses das instituições dominantes, dos valores difundidos, dos mecanismos utilizados para manter uma ordem natural de compreensão para o problema da desigualdade, em um processo explicativo que esteja acima de qualquer suspeita. Ausente tal condição, é em um clima de suspeição que se pode pensar na expansão da ralé como uma ocorrência classista intencional, resultante de um abandono político e social, legitimado nas práticas cotidianas por séculos a fio, geração pós geração.

Ao refletir sobre os impactos da dimensão subjetiva na construção e na manutenção da subcidadania, entendida como produto da profunda desigualdade social existente no País, muitos questionamentos ainda exigem respostas: Que componentes relacionais sustentam esse processo? Como os sujeitos se vinculam de maneira diferenciada a partir da posição que o outro ocupa na hierarquia social? Como propor mudanças que efetivamente possam encontrar ressonância na sociedade? 
Souza e Luna (2009) destacam que uma pessoa que se acostumou a não ser tratada como cidadã muitas vezes não sabe como exigir benefícios, que, não obstante serem garantidos em lei, exigiriam a organização de ações, a disciplina e 0 autocontrole que não possuem.
De acordo com Souza (2009), esclarecer a desigualdade e a marginalidade brasileira impõe restaurar, obrigatoriamente, a discussão teórica em torno da ambiguidade característica de toda sociedade moderna, que é a de se supor igualitária e justa e ser, em ato, desigual e injusta. Esse processo, contudo, não está posto de um modo estanque, mas é continuamente moldado e consolidado por meio das vivências subjetivas individuais e sociais, que se especificam nos processos históricos das nações.

Nesse sentido, a dimensão subjetiva associada à construção e à manutenção da desigualdade social no Brasil pode ser considerada um fenômeno complexo. Martínez (2005) nos alerta que um indivíduo pode abarcar conjuntamente características e concepções contraditórias, em dependência da articulação entre os sentidos subjetivos formados na sua história de vida e os momentos relacionais nas diversas esferas sociais. Desse modo, no que tange à vivência da desigualdade social, podemos observar que estamos imersos em uma subjetividade social de construções histórico-valorativas, a partir da posição ocupada pelas pessoas na hierarquia social, que são incorporadas de modo pré-reflexivo, no sentido bourdiesiano (Bourdieu, 2007, 2009).

Nesse contexto, torna-se necessário alinhar esforços interpretativos para a compreensão da desigualdade social a partir de perspectivas superadoras da dicotomia indivíduosociedade, pois, assim como que a construção social da subcidadania - bem como os demais efeitos do modo como a desigualdade social se consolidou e se retroalimenta no Brasil - tem um componente estrutural relativo à subjetividade social, esta última também se perpetua pela ação pré-reflexiva de cada sujeito na vivência de sua subjetividade individual. As configurações subjetivas construídas no âmbito social não aparecem como algo externo, em contraposição às configurações das subjetividades individuais, mas constituem-se mutuamente, uma vez que não é possível considerar a subjetividade de um espaço social desatrelada da subjetividade dos indivíduos que a compõem. De modo análogo, não é possível compreender a constituição da subjetividade individual sem apreciar a subjetividade dos espaços sociais que colaboram para a sua construção (Martínez, 2005).

Toda produção de sentidos subjetivos é fruto da tensão entre os sentidos que surgem no decorrer da ação do sujeito e os sentidos que precedem esse momento (Rey, 2005b). A responsabilidade pela superação dos efeitos da desigualdade social na ralé possui aspectos de cunho individual, na medida em que apontam o modo de vinculação entre os sujeitos em nossa sociedade, contudo, também inclui uma responsabilidade coletiva, dada a necessidade de democratização das oportunidades (Souza, 2010).

Em uma perspectiva complementar, o conceito de subcidadania desenvolvido por Souza pode ser compreendido frente às teorizações de Rey de que a subjetividade social atravessa de modo constante a individualidade, motivo pela qual se observa que a subjetividade individual é capaz de produzir novos sentidos subjetivos de acordo, também, com o espaço social em que a ação do sujeito se desdobra. No curso do seu desenvolvimento, o sentido subjetivo torna-se, de certa forma, independente dos processos simbólicos e das emoções originais que o determinaram, e estende-se de muitas formas não identificáveis, tanto para o sujeito como para seu entorno.

Entretanto, Luna (2009) destacam que uma pessoa que se acostumou a não ser tratada como cidadã muitas vezes não sabe como exigir benefícios, que, não obstante serem garantidos em lei, exigiriam a organização de ações, a disciplina e o autocontrole que não possuem. Esse processo guarda profunda 
correlação com o modo como se estruturou e se expressa a subjetividade desses sujeitos através dos processos disponíveis para tal em nossa sociedade. Necessário se faz, portanto, dar visibilidade ao tema da desigualdade social, destacando seus componentes subjetivos, os quais constroem e retroalimentam a noção de subcidadania atribuída à ralé, contribuindo para a manutenção da desigualdade social no Brasil.

Convergente com as hegemônicas concepções dicotômicas, que discriminam sujeito e sociedade como âmbitos distintos e independentes, a perspectiva sociológica assegura a supremacia da afirmação da dimensão social, enquanto, na perspectiva psicológica, o destaque é para a dimensão individual, a despeito das perspectivas superadoras da dicotomia indivíduo-sociedade apresentadas neste trabalho. Contudo, uma vez que sociedades formam indivíduos e indivíduos estruturam sociedades, tais visões deveriam ser integrativas e complementares.

A ênfase na possibilidade de os sujeitos produzirem novos sentidos subjetivos (Rey, 2005b) e de transformarem a realidade ao seu redor pode contribuir para relativizar a sensação de determinismo implícito presente nos estudos sobre a desigualdade social brasileira e de subcidadania. Entretanto, para que tal processo ocorra, observa-se a necessidade de um suporte social efetivo ao sujeito, que seja capaz de favorecer transformações do seu habitus.

Os sujeitos constroem uma forma única e particular de produção de sentidos, e, ao desenvolverem diferentes tipos de atividades, as configurações subjetivas se constituiriam de forma diferenciada nas expressões de cada um deles, já que não estariam determinados somente por forças externas, que atuam em relação a eles; ao contrário, apresentariam condições de expressar seu potencial criativo através do exercício de opções pessoais, modificando as condições supostamente determinadas na constituição da ralé brasileira. Contudo, cabe questionar: há espaço para a expressão da ralé em nossa sociedade? 


\section{Luane Neves Santos}

Mestre em Psicologia pela Universidade Federal da Bahia, Salvador - BA - Brasil.

E-mail: luanepsi@yahoo.com.br

\section{Alessivânia Márcia assunção Mota}

Mestre em Psicologia Social e do Trabalho pela Universidade Federal da Bahia, Salvador - BA - Brasil.

E-mail: alessivania@hotmail.com

\section{Marcus Vinícius de Oliveira Silva}

Doutor em Saúde Coletiva pela Universidade do Estado do Rio de Janeiro e docente da Universidade Federal da Bahia, Salvador - BA - Brasil

E-mail: matraga2@uol.com.br

\section{Endereço para envio de correspondência:}

Rua Aristides Novis, 197, Federação. CEP: 40210-909. Salvador, BA.

Recebido 25/03/2012, 1a Reformulação 14/12/2012, Aprovado 11/04/2013. 
Bock, A. (1999). A psicologia a caminho do novo século: identidade profissional e compromisso social. Estudos de Psicologia, 4(2), 315-329.

Bock, A., Gonçalves, M. G. M., \& Furtado, O. (2009). Psicologia sócio-histórica (uma perspectiva crítica em psicologia) (4a ed.). São Paulo: Cortez Editora.

Bourdieu, P. (2007). A distinção: crítica social do julgamento. São Paulo: Edusp; Porto Alegre: Zouk.

Bourdieu, P. (2009). O senso prático (M. Ferreira, Trad.). Rio de Janeiro: Vozes.

Costa, F. B. da. (2004). Homens invisíveis: relatos de uma humilhação social. São Paulo: Globo.

Elias, N. (1994). A sociedade dos indivíduos. Rio de Janeiro: Zahar.

Fernandes, F. (1978). A integração do negro na sociedade de classes (3a ed.) São Paulo: Ática.

Figueiredo, L.C., \& Santi, P. L. R. (2003). Psicologia - uma (nova) introdução. São Paulo: Educ. (série Trilhas).

Gonçalves Filho, J. M. (1998). Humilhação social - um problema político em psicologia. Psicol. USP, 9(2), 11-67.

Instituto Brasileiro de Geografia e Estatística - IBGE. (2010). Indicadores de desenvolvimento sustentável: Brasil 2010. Rio de Janeiro.

Lahire, B. (2008). Esboço do programa científico de uma sociologia psicológica. Educação e Pesquisa, 34(2), 373-389.

Luna, L. (2009). Fazer viver e deixar morrer: a má-fé da saúde pública no Brasil. In J. Souza (Org.), A ralé brasileira: quem é e como vive. Belo Horizonte, MG: Editora da UFMG. (Coleção Humanitas).

Martínez, A. M. (2005). A teoria da subjetividade de González Rey: uma expressão do paradigma da complexidade na Psicologia. In F. G. Rey, (Org.). Subjetividade, complexidade e pesquisa em psicologia (pp.1-25). São Paulo: Pioneira Thomson Learning.

Marx, K. (1988). O capital. Coleção Os Economistas. São Paulo: Nova Cultural.
Morin, E. (2000). A cabeça bem feita: repensar a reforma, reformar o pensamento (8a ed.). (Jacobina, E., Trad.). Rio de Janeiro: Bertrand Brasil (Trabalho original publicado em 1921).

Neri, M. (2011). Desigualdade de renda na década. São Paulo: FGV/CPS. Recuperado em 31 jul., 2011, do Centro de Políticas Sociais da FGV: http://cps.fgv.br/desiguladade_de_ renda na decada.

Patto, M. H. S. (1984). Psicologia e ideologia: uma introdução crítica à psicologia escolar. São Paulo: T. A. Queiroz.

Rey, F. G. (2005a). Pesquisa qualitativa e subjetividade. São Paulo: Thomson.

Rey, F. G. (2005b). Sujeito e subjetividade. São Paulo: Thomson.

Rey, F. G. R. (2005c). Subjetividade, complexidade e pesquisa em psicologia. São Paulo: Thomson.

Sawaia, B. (2001). As artimanhas da exclusão: análise psicossocial e ética da desigualdade social. Petrópolis, RJ: Vozes.

Souza, J. (2003). A construção social da subcidadania: por uma sociologia política da modernidade periférica. Belo Horizonte, MG: Editora UFMG; Rio de Janeiro: IUPERJ. (Coleção Origem).

Souza, J. (2006a). Apresentação. In J. Souza (Org.), A invisibilidade da desigualdade brasileira (pp. 9-21). Belo Horizonte, MG: Editora UFMG.

Souza, J. (2006b). A gramática social da desigualdade brasileira. In J. Souza (Org.). A invisibilidade da desigualdade brasileira (pp. 23-53). Belo Horizonte, MG: Editora UFMG.

Souza, J. (2006c). Réplica a Luiz Eduardo Soares (entrevista ao site acessa.com) Recuperado em 15 de janeiro, 2011 de www. acessa.com/gramsci/?page $=$ visualizar $\& i d=503$.

Souza, J. (2009). A ralé brasileira: quem é e como vive. Belo Horizonte, MG: Editora da UFMG. (Coleção Humanitas).

Souza, J. (2010). Os batalhadores brasileiros: nova classe média ou nova classe trabalhadora. Belo Horizonte, MG: Editora da UFMG. (Coleção Humanitas).

Spink, M. J. P., \& Spink, P. (2005). Introdução. In M. J. P. Spink \& P. Spink (Orgs.), Práticas cotidianas e a naturalização da desigualdade: uma semana de notícias nos jornais (pp. 7-16). São Paulo: Cortez. 